\title{
Caffeine Attenuates Waking and Sleep Electroencephalographic Markers of Sleep Homeostasis in Humans
}

\author{
Hans-Peter Landolt*,', Julia V Rétey', Karin Tönz', Julie M Gottselig', Ramin Khatami', \\ Isabelle Buckelmüller' and Peter Achermann' \\ 'Institute of Pharmacology \& Toxicology, University of Zürich, Zürich, Switzerland
}

\begin{abstract}
Prolonged wakefulness increases electroencephalogram (EEG) low-frequency activity $(<10 \mathrm{~Hz}$ ) in waking and sleep, and reduces spindle frequency activity $(\sim 12-16 \mathrm{~Hz})$ in non-rapid-eye-movement (nonREM) sleep. These physiologic markers of enhanced sleep propensity reflect a sleep-wake-dependent process referred to as sleep homeostasis. We hypothesized that caffeine, an adenosine receptor antagonist, reduces the increase of sleep propensity during waking. To test this hypothesis, we compared the effects of caffeine and placebo on EEG power spectra during and after $40 \mathrm{~h}$ of wakefulness. A total of 12 young men underwent two periods of sleep deprivation. According to a randomized, double-blind, crossover design, they received two doses of caffeine $(200 \mathrm{mg})$ or placebo after II and $23 \mathrm{~h}$ of wakefulness. Sleep propensity was estimated at 3-h intervals by measuring subjective sleepiness and EEG theta (5-8 Hz) activity, and polysomnographic recordings of baseline and recovery nights. Saliva caffeine concentration decreased from $15.7 \mu \mathrm{mol} / \mathrm{l} 16 \mathrm{~h}$ before the recovery night, to $1.8 \mu \mathrm{mol} / \mathrm{l} \mathrm{I} \mathrm{h}$ before the recovery night. Compared with placebo, caffeine reduced sleepiness and theta activity during wakefulness. Compared with sleep under baseline conditions, sleep deprivation increased $0.75-8.0 \mathrm{~Hz}$ activity and reduced spindle frequency activity in nonREM sleep of the recovery nights. Although caffeine approached undetectable saliva concentrations before recovery sleep, it significantly reduced EEG power in the $0.75-2.0 \mathrm{~Hz}$ band and enhanced power in the $11.25-20.0 \mathrm{~Hz}$ range relative to placebo. These findings suggest that caffeine attenuated the build-up of sleep propensity associated with wakefulness, and support an important role of adenosine and adenosine receptors in the homeostatic regulation of sleep.

Neuropsychopharmacology (2004) 29, 1933-1939, advance online publication, I4 July 2004; doi: I 0.1038/sj.npp. 1300526
\end{abstract}

Keywords: adenosine; sleep regulation; sleep propensity; spectral analysis; intermittent naps

\section{INTRODUCTION}

Sleep is homeostatically regulated (Borbély and Achermann, 2000). Changes in sleep propensity following deviations of sleep duration from an average 'reference value' are counteracted not only by changes in sleep duration but also by changes in sleep intensity. Electroencephalogram (EEG) low-frequency activity (spectral power $<10 \mathrm{~Hz}$ ) and spindle frequency activity (SFA, power within $12-16 \mathrm{~Hz}$ ) in non-rapid-eye-movement (nonREM) sleep serve as physiologic markers of sleep intensity. Low-frequency activity rises as a function of time awake and declines during sleep, whereas SFA is reduced after sleep deprivation (Borbély

\footnotetext{
*Correspondence: Dr H-P Landolt, Institute of Pharmacology \& Toxicology, University of Zürich, Winterthurerstrasse 190, 8057 Zürich, Switzerland, Tel: +4| | 635 5953, Fax: +4| | 635 5707,

E-mail: landolt@pharma.unizh.ch

Received II March 2004; revised I 8 May 2004; accepted I 4 June 2004 Online publication: 16 June 2004 at http://www.acnp.org/citations/ NPP06 | 60404 | | |/default.pdf
}

et al, 1981; Dijk et al, 1993; Landolt et al, 2000; Finelli et al, 2001).

Caffeine is an adenosine receptor antagonist (Fredholm et al, 1999; Dunwiddie and Masino, 2001). The neuromodulator adenosine may be critically involved in sleep homeostasis (Radulovacki, 1993; Benington and Heller, 1995; Porkka-Heiskanen et al, 1997, 2002). Consistent with this hypothesis, a bedtime dose $(100 \mathrm{mg})$ of caffeine decreased EEG spectral power between 1.25 and $2.0 \mathrm{~Hz}$ and increased power between 13.25 and $15.0 \mathrm{~Hz}$ in nonREM sleep (Landolt et al, 1995a). Remarkably similar and longlasting effects were found at night after morning caffeine $(200 \mathrm{mg})$ intake even when the saliva caffeine concentration approached zero (Landolt et al, 1995b). Together with a study in rats (Schwierin et al, 1996), these findings indicated that the homeostatic process build-up during wakefulness can be attenuated by caffeine.

An EEG correlate of sleep homeostasis can now be tracked also during wakefulness. Power in the theta band of the waking EEG increases during sleep deprivation (Torsvall and Akerstedt, 1987; Cajochen et al, 1995; Aeschbach et al, 
1997; Finelli et al, 2000). The time constant of this increase is similar to that of the wake-dependent increase of lowfrequency activity in nonREM sleep (Cajochen et al, 1995; Aeschbach et al, 1997). A positive correlation between the rise rate of theta activity $(5-8 \mathrm{~Hz})$ in waking and the enhancement of low-frequency activity $(0.75-4.5 \mathrm{~Hz})$ in nonREM sleep after sleep deprivation indicated that these variables are closely related (Finelli et al, 2000). Although caffeine reduced theta activity in the waking EEG for 1-4h (Künkel, 1976; Dimpfel et al, 1993), the involvement of adenosine and adenosine receptors in homeostatic sleep regulation is still uncertain (Wurts and Edgar, 2000; Van Dongen et al, 2001; Stenberg et al, 2003).

To further elucidate the role of adenosine in sleep homeostasis, we investigated whether caffeine attenuates the increase of subjective sleepiness during prolonged wakefulness and affects the EEG correlates of sleep propensity across the wake-sleep continuum. Sleepiness and theta activity do not rise in a monotonic fashion, but are also modulated by the endogenous circadian clock (Aeschbach et al, 1997, 1999; Dumont et al, 1999; Finelli et al, 2000; Cajochen et al, 2002). When sleep is terminated in the morning, these variables are low throughout the first $15-20 \mathrm{~h}$ of waking, increase steeply when the subjects usually sleep, and peak early during the second day of wakefulness. To investigate the effects of caffeine at times of low and high levels of sleepiness and EEG theta power, two doses were administered, after 11 and $23 \mathrm{~h}$ of a 40 -h period of waking. This intake pattern minimized acute caffeine effects on recovery sleep, which began $17 \mathrm{~h}$ after the second dose. Based on our previous observation that morning caffeine induced sleep EEG changes indicative of attenuated sleep propensity in subjects who were not sleep deprived (Landolt et al, 1995b), we predicted that caffeine, as compared with placebo, would induce similar changes in the sleep EEG during recovery sleep after sleep deprivation.

\section{METHODS}

\section{Subjects and Procedures}

Participants were healthy male students $(n=12$; mean age: 25.3 years; range: $20-30$ years) with a mean body mass index of $23.7 \mathrm{~kg} / \mathrm{m}^{2}$ (range: $20.4-28.7 \mathrm{~kg} / \mathrm{m}^{2}$ ) recruited from the University of Zürich and the Swiss Federal Institute of Technology. They were paid for participation in the study. They reported having no medical history of neurologic and psychiatric disease, being in good health and not taking any medication or having consumed illicit drugs at least 2 months before the study. All were nonsmokers and reported habitual consumption of less than five alcoholic drinks per week, and less than $300 \mathrm{mg}$ caffeine (in beverages such as coffee, tea, cola drinks) per day. Their sleep questionnaires revealed that they were good sleepers with regular bedtimes and no subjective sleep disturbances. Upon reception of their written informed consent, they were screened by polysomnography in the sleep laboratory to exclude sleep apnea and periodic limb movements in sleep (PLMS). Subjects with a sleep apnea and/or a PLMS index of 5 or more per hour of sleep, or a sleep efficiency of lower than $80 \%$ were excluded from participation in the study.
The local ethics committee for research on human subjects approved the study protocol, which was carried out in accordance with the Declaration of Helsinki. It consisted of two blocks of four consecutive nights separated by 1 week. In each block, the first and second nights served as adaptation and baseline nights, respectively. The subjects then stayed awake for $40 \mathrm{~h}$ (ie for 2 days, skipping one night of sleep) until bedtime of the fourth (recovery) night. During the period of extended wakefulness, the volunteers were under continuous supervision of a member of the research team and engaged in studying, playing games, watching films, and occasionally taking a walk outside the laboratory.

During the 2 weeks prior to the study, the subjects were asked to abstain from all caffeine (coffee, tea, cola drinks, chocolate, energy drinks), to wear a wrist-activity monitor on the nondominant arm, and to keep a sleep-wake diary. During the 3 days prior to the study, the participants were instructed to abstain also from ethanol and to maintain a regular sleep-wake cycle with sleep scheduled from 2300 to $0700(n=4)$ or from 2400 to $0800(n=8)$ according to their questionnaires and sleep diaries. They were not allowed to deviate from these bedtimes by more than $1 \mathrm{~h}$. Compliance with this instruction was verified by inspection of the restactivity plots. Abstinence from alcohol and caffeine was verified on sleep recording days by determining the breath ethanol concentration and the saliva caffeine level upon arrival in the sleep lab.

In the adaptation and baseline nights, sleep was scheduled from 2300 to $0700(n=4)$ or from 2400 to $0800(n=8)$. The recovery nights started at $2300(n=4)$ or $2400(n=8)$ and lasted $10.5 \mathrm{~h}$. The analyses reported here were restricted to the first $480 \mathrm{~min}$ after lights-out.

Two doses of $200 \mathrm{mg}$ caffeine were administered to each subject during sleep deprivation according to a randomized, placebo-controlled, double-blind, crossover design. The first dose was given $11 \mathrm{~h}$ after waking from the baseline night (at 1800 or 1900), and the second dose after $23 \mathrm{~h}$ waking (at 0600 or 0700 ). The kinetics of saliva caffeine concentration was followed. Samples were collected $5 \mathrm{~min}$ before and 30 and $60 \mathrm{~min}$ after caffeine intake, and at 3-h intervals immediately before all waking EEG recordings that followed the first dose of caffeine. The samples were stored at $-20^{\circ} \mathrm{C}$ and later analyzed for caffeine with a homogenous enzyme immunoassay $\left(\right.$ Emit $^{\circledR}$-Caffeine Test, Syva Company, Palo Alto, CA) (Oellerich, 1980).

Self-rated sleepiness during sleep deprivation was quantified every $3 \mathrm{~h}$ with a German translation of the Stanford Sleepiness Scale (Sturm and Clarenbach, 1997).

\section{Waking EEG Recordings}

The waking EEG was recorded intermittently in 14 sessions at 3-h intervals starting $15 \mathrm{~min}$ after lights-on at the end of the baseline nights. To record the waking EEG, participants were instructed to relax comfortably in a chair at a desk in the sleeping room and to place their chin on an individually adjusted head-rest. Each recording consisted of a 3-min period with eyes closed, followed by a 5 -min period with eyes open while fixating a black dot at a distance of $3 \mathrm{~m}$ attached to the wall. When signs of drowsiness were detected (eg reduced EEG alpha activity and rolling eye 
movements), the subjects were alerted by addressing them over the intercom. At $1 \mathrm{~h}$ before each waking EEG, the subjects had to stay in the laboratory (constant temperature, light intensity $<150 \mathrm{lux}$ ), and $15 \mathrm{~min}$ before the recordings they remained in their bedrooms where they were free to read or write.

The EEG (data from the $\mathrm{C} 3 \mathrm{~A} 2$ derivation are reported here), electro-oculogram (EOG), submental electromyogram (EMG), and electrocardiogram (ECG) were recorded using a polygraphic amplifier (PSA24, Braintronics Inc., Almere, The Netherlands). The analog signals were conditioned by a high-pass filter $(-3 \mathrm{~dB}$ at $0.16 \mathrm{~Hz})$, a low-pass filter $(-3 \mathrm{~dB}$ at $102 \mathrm{~Hz}$ and approximately $-40 \mathrm{~dB}$ at $256 \mathrm{~Hz})$, and a notch filter $(50 \mathrm{~Hz})$, digitized and transmitted via fiber-optic cables to a personal computer. Data were sampled with a frequency of $512 \mathrm{~Hz}$, digitally filtered (EEG and EOG: low-pass FIR filter, $-3 \mathrm{~dB}$ at $49 \mathrm{~Hz}$; EMG: bandpass FIR filter, $-3 \mathrm{~dB}$ at 15.6 and $54 \mathrm{~Hz}$ ) and stored on a hard disk with a resolution of $128 \mathrm{~Hz}$. EEG artifacts were identified by visual inspection. Power spectra, conditioned by application of a Hanning window and linear detrending, were computed off-line by a fast Fourier transform (FFT) routine (MATLAB ${ }^{\circledR}$, The MathWorks Inc., Natick, MA). Theta activity (power within $5-8 \mathrm{~Hz}$ ) during the 5-min periods with eyes open was computed for each artifact-free 2-s epoch and averaged across these epochs for each session. Electrode impedance was checked regularly, and electrodes were replaced when necessary.

Relative theta activity (EEG power within $5-8 \mathrm{~Hz}$ ) was expressed as a percentage of the mean value over the first four waking EEG recordings, that is, before placebo and caffeine administration, respectively.

\section{Polysomnographic Recordings}

Continuous all-night polysomnographic recordings were performed during all experimental nights. The EEG, EOG, EMG, and ECG data were recorded, filtered, digitized, and stored on a hard disk in the same way as the waking EEG data. The power spectra of consecutive 4 -s epochs $(10 \%$ cosine window) were computed on-line by an FFT routine resulting in a frequency resolution of $0.25 \mathrm{~Hz}$. Values above $20 \mathrm{~Hz}$ were omitted and adjacent bins were averaged into $0.5 \mathrm{~Hz}(0.25-5.0 \mathrm{~Hz})$ and $1.0 \mathrm{~Hz}(5.25-20.0 \mathrm{~Hz})$ bins. The sleep stages were visually scored for 20-s epochs according to standard criteria (Rechtschaffen and Kales, 1968). The 4second epochs with movement- and arousal-related artifacts were visually identified and eliminated. Power spectra of five consecutive 4-s epochs were averaged and matched with the sleep scores.

\section{Data Analyses and Statistics}

The caffeine concentration in saliva, subjective sleepiness ratings, EEG power spectra in waking and sleep (stages $2-4)$, and visually scored sleep variables were analyzed. For data analyses, the SAS ${ }^{\circledR}$ statistical software (SAS Institute Inc., Cary, NC) was used. Because the two baseline sleep episodes did not differ for any variable, the recovery sleep episodes (ie SD-Placebo and SD-Caffeine) were compared with the average of the two baseline nights. Two- and threeway analyses of variance for repeated measures (rANOVA) with the between-factor order (caffeine-placebo, placebocaffeine) and the within-factors condition (baseline, SDPlacebo, SD-Caffeine), treatment (placebo, caffeine), time of caffeine administration (evening, morning), and 3-h time interval (14 time points across sleep deprivation) were performed to estimate the effects of caffeine and prolonged waking. No analysis revealed a significant order effect or a significant interaction involving the factor order. For factors with more than two levels, the Huynh-Feldt-corrected degrees of freedom were computed, but the original degrees of freedom are reported. The significance level was set at $\alpha=0.05$. To approximate a normal distribution, values of sleep latency, REM sleep latency, and absolute power densities were log-transformed prior to statistical tests.

\section{RESULTS}

\section{Caffeine Concentration in Saliva}

The time course of caffeine in saliva during sleep deprivation is illustrated in Figure 1a. Prior to drug intake, the caffeine level was below the limit of detection $(5.2 \mu \mathrm{mol} /$ 1) in all subjects. A $200 \mathrm{mg}$ dose of caffeine after 11 and $23 \mathrm{~h}$ waking led to mean maximum saliva concentrations of $9.8 \pm 1.6 \mu \mathrm{mol} / \mathrm{l}( \pm \mathrm{SEM}, \quad n=12)$ and $15.7 \pm 2.1 \mu \mathrm{mol} / \mathrm{l}$, respectively. At $1 \mathrm{~h}$ before lights-out, caffeine was below the detection limit in nine individuals, and 10.2, 6.4, and $5.5 \mu \mathrm{mol} / 1$ in the remaining subjects (mean concentration: $1.8 \pm 1.0 \mu \mathrm{mol} / \mathrm{l}$; samples with caffeine below the detection limit were assigned a value of zero).

\section{Subjective Sleepiness}

Subjective sleepiness increased nonmonotonically from the first to the second day of sleep deprivation (Figure 1b, three-way rANOVA with factors order, interval, and treatment; factor interval, $\left.\mathrm{F}_{13,130}=41.5, p<0.001\right)$. Whereas a significant effect of pharmacological treatment was found $\left(\mathrm{F}_{1,10}=6.7, p<0.03\right)$, no significant treatment $\times$ interval interaction emerged $\left(\mathrm{F}_{13,130}=1.5, p>0.1\right)$. The mean subjective sleepiness rating across the final 29-h waking period was lower in the caffeine condition than in the placebo condition $(3.2 \pm 0.1$ vs $3.7 \pm 0.2$; one-way rANOVA with factor treatment, $\left.\overline{\mathrm{F}}_{1,11}=5.8, \bar{p}<0.04\right)$, whereas it did not differ before caffeine and placebo administration $\left(1.9 \pm 0.1\right.$ vs $\left.2.1 \pm 0.1 ; \mathrm{F}_{1,11}=1.3, p>0.2\right)$.

\section{EEG Theta Activity during Waking}

Repeated waking EEG recordings were conducted at 3-h intervals throughout the sleep deprivation period. Theta activity increased during prolonged wakefulness and also a circadian modulation was evident (factor interval, $\left.\mathrm{F}_{13,130}=7.3, p<0.001\right)$. The evolution of theta activity during sleep deprivation differed between the pharmacological conditions, as evidenced by a significant treatment $\times$ interval interaction $\left(\mathrm{F}_{13,130}=2.4, p<0.03\right.$; factor treatment, $\left.\mathrm{F}_{1,10}=12.2, p<0.006\right)$. Compared with placebo, theta activity was reduced 1,4 , and $7 \mathrm{~h}$ after the first, and 1 and $4 \mathrm{~h}$ after the second dose of caffeine (minimum $\left.\mathrm{F}_{1,11}=5.0, p<0.05\right)$. 


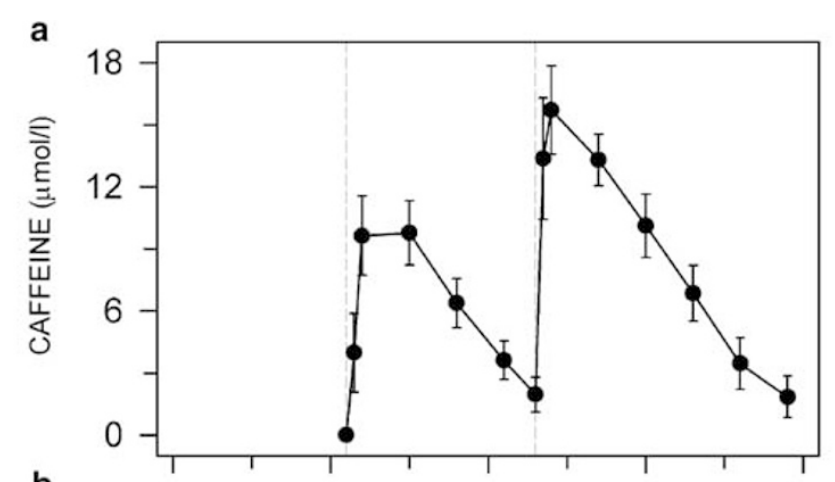

b

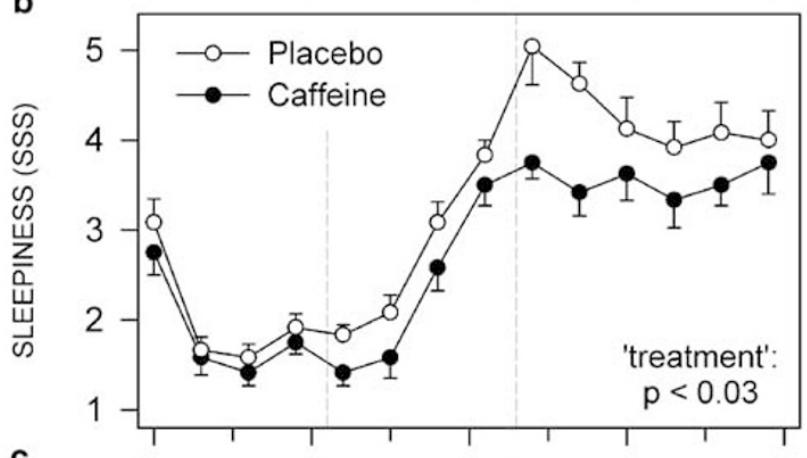

C

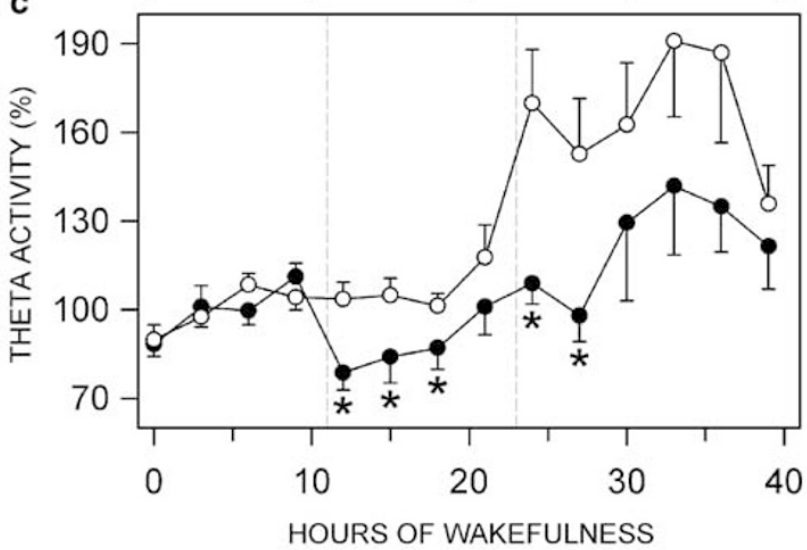

Figure I Time course of (a) saliva caffeine concentration, (b) subjective sleepiness (Stanford Sleepiness Scale), and (c) EEG theta activity (C3A2 derivation, power within $5-8 \mathrm{~Hz}$ ) across $40 \mathrm{~h}$ waking. Sleepiness ratings and theta activity are plotted for consecutive 3-h intervals of the placebo (open circles) and caffeine conditions (filled circles), respectively. Theta activity is expressed as a percentage of mean theta activity in the first four waking EEG recordings (at $0,3,6$, and $9 \mathrm{~h}$ waking). Error bars represent SEM $(n=12)$. Caffeine $(200 \mathrm{mg})$ was administered at II and $23 \mathrm{~h}$ waking (vertical dashed lines). The asterisks indicate the time intervals with significant treatment effects $(p<0.05$, one-way rANOVA with factor treatment).

To investigate the interaction between caffeine and the homeostatic build-up of sleep propensity as reflected in the waking EEG, the reduction of theta activity was analyzed $1 \mathrm{~h}$ after evening ( $11 \mathrm{~h}$ waking) and morning ( $23 \mathrm{~h}$ waking) caffeine administration. In comparison with placebo, theta power was reduced by $22.5 \pm 6.0 \%$ in the evening and $31.8 \pm 5.1 \%$ in the morning, respectively. These druginduced changes in the waking EEG differed, as indicated by a significant treatment $\times$ time interaction $\left(\mathrm{F}_{1,10}=4.8\right.$, $p=0.05$; factor treatment, $\mathrm{F}_{1,10}=29.0, p<0.001$; factor time, $\left.\mathrm{F}_{1,10}=24.1, p<0.001\right)$. The reduction in theta activity was not associated with the caffeine saliva concentration (Pearson's product-moment correlation: $r_{\text {evening }}=-0.49$, $p>0.1$ and $r_{\text {morning }}=-0.44, p>0.1, n=12$ ).

\section{EEG Power Spectra during Recovery Sleep}

The effects of sleep deprivation and caffeine on EEG power spectra in nonREM sleep during the first $480 \mathrm{~min}$ of the recovery sleep episodes are illustrated in Figure 2. The sleep deprivation effect consisted of an increase of power in delta and theta frequencies $(0.25-8.0 \mathrm{~Hz})$, and a decrease in the sigma/beta frequency range (placebo: $11.25-19.0 \mathrm{~Hz}$; caffeine: $13.25-15.0 \mathrm{~Hz}$ ). Consistent with previous sleep deprivation studies (Borbély et al, 1981; Dijk et al, 1993; Landolt et al, 2000; Finelli et al, 2001), the increase in lowfrequency power was largest in the low delta range $(<3 \mathrm{~Hz})$. Compared with placebo, caffeine attenuated the increase of power in the $0.75-2.0 \mathrm{~Hz}$ range (factor treatment, minimum $\left.\mathrm{F}_{1,11}=5.1, p<0.05\right)$ and the reduction of power in the entire $11.25-20.0 \mathrm{~Hz}$ band (minimum $\mathrm{F}_{1,11}=7.9, p<0.02$ ).

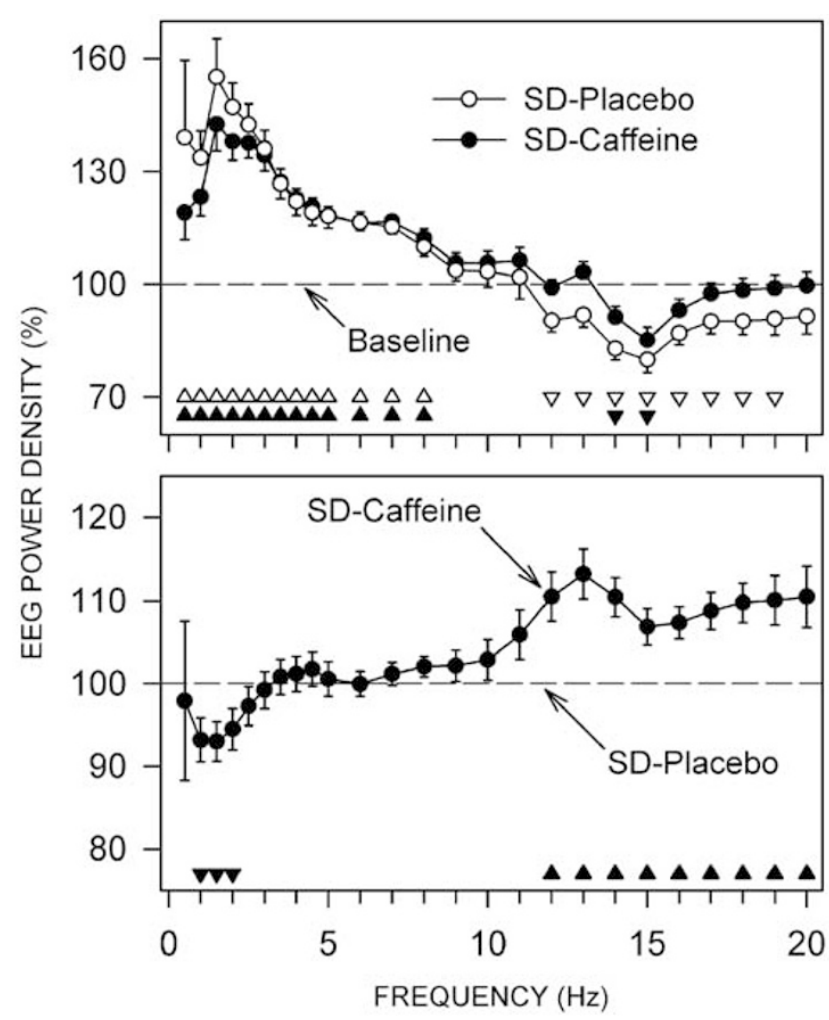

Figure 2 Relative EEG power spectra (C3A2 derivation) in nonREM sleep (stages 2-4) of the placebo (SD-Placebo, open circles) and caffeine (SD-Caffeine, filled circles) recovery sleep episodes after $40 \mathrm{~h}$ waking. Spectra were computed for the first $480 \mathrm{~min}$ from lights-out. For each frequency bin, means $(n=12$, SEM) are expressed as a percentage of the corresponding mean value of the baseline nights (top) or the SD-Placebo night (bottom, horizontal dashed lines indicate 100\%). Values are plotted at the upper limit of 0.5 - or 1.0- $\mathrm{Hz}$ bins. Triangles above the abscissae denote frequency bins for which power differed significantly from baseline (SDPlacebo, $\Delta$; SD-Caffeine, $\mathbf{\Delta}$ ) or SD-Placebo conditions (one-way rANOVA with factor treatment). Orientation of triangles indicates the direction of deviation. 


\section{Visually Scored Sleep Variables}

The distinct changes in visually scored sleep variables that typically follow sleep deprivation were present after both caffeine and placebo administration. Compared with baseline, total sleep time, sleep efficiency, and slow-wave sleep were increased, while sleep latency, stage 1 sleep, and wakefulness after sleep onset were decreased (Table 1). All values were remarkably similar in both treatment conditions and did not differ between caffeine and placebo.

\section{DISCUSSION}

The main findings of this study are that the adenosine receptor antagonist caffeine attenuated the effects of sleep deprivation on electrophysiological correlates of sleep homeostasis in waking and sleep. The data are consistent with the hypothesis that some sleep deprivation-induced changes in the EEG during waking (ie increase in theta activity) and sleep (ie increase in low-frequency activity, decrease in SFA) are mediated via the adenosinergic system. Moreover, the findings corroborate and extend our previous observation that $200 \mathrm{mg}$ caffeine in the early morning reduces low-frequency activity and enhances SFA in nonREM sleep in the subsequent night (Landolt et al, 1995b). We are now investigating whether caffeine affects the waking and sleep EEG with regional specificity (Finelli et al, 2000, 2001), and differently in subjects with high and low subjective caffeine sensitivity.

In accordance with our previous report (Landolt et al, 1995b), $200 \mathrm{mg}$ caffeine resulted in saliva levels of 9.8 and $15.7 \mu \mathrm{mol} / 1 \mathrm{~h}$ after drug intake (Figure 1a). After oral administration of $100-300 \mathrm{mg}$ caffeine, the ratio between the concentrations in saliva and plasma equals approximately 0.8 (Zylber-Katz et al, 1984; Haeckel, 1990). The measured saliva levels correspond thus to plasma levels of approximately $2.5-4.5 \mu \mathrm{g} / \mathrm{ml}$ (Kaasinen et al, 2004). A very similar caffeine concentration was observed in a recent study, in which 15 subjects received a sustained low dose of $0.3 \mathrm{mg} / \mathrm{kg}$ caffeine at hourly intervals during the last $66 \mathrm{~h}$ of an $88-\mathrm{h}$ waking period (Van Dongen et al, 2001). In comparison with an independent group of 13 subjects receiving placebo, no consistent effects of caffeine were found on nonREM sleep duration and cumulative slow-wave activity (ie slowwave energy) in nonREM sleep during five 2-h naps. Based on these and findings in rats (Wurts and Edgar, 2000), the proposed inhibitory effect of caffeine on the homeostatic drive for sleep was questioned (Van Dongen et al, 2001). It could be, however, that a ceiling effect after prolonged wakefulness led to similar nonREM sleep durations in all naps irrespective of treatment (the first nap occurred after $>25 \mathrm{~h}$ of waking). Moreover, a high interindividual variability in slow-wave energy may have obscured subtle effects of low-dose caffeine in the between-groups comparison.

To estimate the build-up of sleep propensity associated with wakefulness, the time course of subjective sleepiness and theta frequency activity $(5-8 \mathrm{~Hz})$ in the waking EEG was quantified at 3-h intervals. Both variables increased with the increasing duration of wakefulness, and also a circadian modulation was present. Consistent with the notion that theta power in the waking EEG represents an objective measure of sleepiness (Akerstedt and Gillberg, 1990; Cajochen et al, 1995; Aeschbach et al, 1999; Dumont et al,

Table I Visually Scored Sleep Variables

\begin{tabular}{|c|c|c|c|c|}
\hline Variable & Baseline & SD-Placebo & SD-Caffeine & $F_{2,20}(p)$ \\
\hline Recording time (min) & 480.0 & 480.0 & 480.0 & \\
\hline Total sleep time (min) & $445.1 \pm 14.5$ & $468.6 \pm 3.8 * * *$ & $467.9 \pm 2.0 * * *$ & $24.6(0.001)$ \\
\hline Sleep efficiency (\%) & $92.8 \pm 3.0$ & $97.7 \pm 0.8$ **** & $97.6 \pm 0.4 * *$ & $24.7(0.001)$ \\
\hline Sleep latency (min) & $17.6 \pm 14.5$ & $4.2 \pm 3.0 * * *$ & $4.8 \pm 2.9 * * *$ & $9.1(0.008)$ \\
\hline REM sleep latency (min) & $72.5 \pm 14.6$ & $69.2 \pm 13.0$ & $65.4 \pm 10.7$ & $1.9(0.17)$ \\
\hline Stage 3 (min) & $43.1 \pm 8.0$ & $55.1 \pm 12.5 *$ & $55.1 \pm 12.3^{*}$ & $8.5(0.002)$ \\
\hline Stage 4 (min) & $42.5 \pm 20.4$ & $88.6 \pm 23.9 * *$ & $84.6 \pm 33.0 * *$ & $40.3(0.001)$ \\
\hline Slow-wave sleep (min) & $85.6 \pm 21.1$ & $143.7 \pm 27.6 * *$ & $139.7 \pm 34.5^{* * *}$ & $68.5(0.001)$ \\
\hline REM sleep (min) & $94.9 \pm 15.1$ & $97.7 \pm 35.6$ & $98.4 \pm 22.6$ & $0.4(0.61)$ \\
\hline
\end{tabular}

Values represent means $\pm S D(n=12)$ for the first 480 min from lights-out. Baseline: average of two baseline nights; SD-Placebo: recovery night after $40 \mathrm{~h}$ wakefulness and placebo treatment; SD-Caffeine: recovery night after $40 \mathrm{~h}$ wakefulness and caffeine treatment $(2 \times 200 \mathrm{mg})$; sleep efficiency: percentage of total sleep time per $480 \mathrm{~min}$; sleep latency: time from lights-out to the first occurrence of stage 2; REM sleep latency: time from sleep onset to the first occurrence of REM sleep; stages I-4: nonREM sleep stages; REM sleep: rapid-eye-movement sleep; WASO: wakefulness after sleep onset; MT: movement time; W+MT+stage I: accumulated wakefulness, movement time, and stage I after sleep onset.

F- and p-values: factor condition of a two-way ANOVA with the between-factor order (caffeine-placebo, placebo-caffeine) and the within-factor condition (baseline, SD-Placebo, SD-Caffeine). F-ratios exceeding $p=0.00 \mathrm{I}$ are highlighted in bold. $* * * 0.00 \mathrm{I}$, $* p<0.03$ compared with baseline (one-way rANOVA with factor condition). 
1999; Finelli et al, 2000), both variables showed a similar time course and were reduced by caffeine treatment. The stimulant caused an immediate, yet transient pharmacological reduction of theta activity in the evening and in the morning (Figure 1c). More importantly, with respect to sleep regulation, the evolution of theta activity during sleep deprivation showed a statistically significant interaction with pharmacological treatment. The reduction of theta activity was stronger after $23 \mathrm{~h}$ of wakefulness than after $11 \mathrm{~h}$ of waking, when both subjective and objective sleepiness measures were high and low, respectively. Although circadian influences cannot be excluded, the distinct effects of caffeine at times of low and high sleepiness support the conclusion that the drug interacted with a homeostatic sleep regulatory mechanism. This evidence is strengthened by the observation that caffeine induced changes in sleepiness and low-frequency EEG activity in waking that were very similar to those observed in an intermittent-nap protocol (Cajochen et al, 2001). An earlier study did not find an interaction between the effects of caffeine (75 or $150 \mathrm{mg}$ twice daily) on average daily sleep latency in an MSLT protocol and sleepiness after normal and restricted sleep (Rosenthal et al, 1991). It is possible, however, that more sensitive measures of caffeine effects and sleepiness would have revealed a consistent result.

A dissociation between the results derived from visual sleep stage scoring and the results from sleep EEG spectral analysis was also observed in this study. Sleep deprivation shortened sleep latency and increased slow-wave sleep to the same degree irrespective of pharmacological treatment. In contrast, the increase of power in the delta range (0.75$2.0 \mathrm{~Hz}$ ) and the reduction in the sigma/low-beta band $(11.25-20 \mathrm{~Hz})$ in nonREM sleep after sleep deprivation were attenuated after caffeine when compared with placebo (Figure $2 \mathrm{~b}$ ). These results are consistent with our previous findings (Landolt et al, 1995b). Because no differences between the treatments were present in the waking EEG before the recovery night, the caffeine-induced changes in nonREM sleep are unlikely to be due to residual caffeine. Although it is possible that the stimulant differently modified EEG markers of sleep homeostasis in waking and sleep, the data suggest that the changes during sleep reflect an attenuated build-up of sleep propensity during wakefulness. This conclusion is further supported by the fact that the drug-induced changes in the EEG in nonREM sleep closely mimicked the reported reduction in delta activity $(1-2.5 \mathrm{~Hz})$ and the increase in SFA following the physiologic attenuation of sleep propensity by multiple naps (Knoblauch et al, 2002).

The neurochemical substrate of sleep homeostasis is unknown. The transition from the desynchronized EEG in wakefulness to the synchronized EEG in nonREM sleep is postulated to involve tonic membrane hyperpolarization in thalamo-cortico-thalamic and cortical circuits (Steriade et al, 1993; McCormick and Bal, 1997; Steriade, 2003). Sleep spindles are elicited in vitro and in vivo when the membrane potential is hyperpolarized to an intermediate level. At more negative membrane potentials, the interburst intervals are similar to the duration of delta waves (McCormick and Bal, 1997; Steriade, 2003). Excessive and more rapid membrane hyperpolarization of these networks may underlie the homeostatic changes in slow-wave activity and SFA after sleep deprivation (Borbély et al, 1981; Dijk et al, 1993; Landolt et al, 2000; Finelli et al, 2001). Two distinct mechanisms are known to increase inhibitory ionic conductance in the central nervous system (reviewed by Benington and Heller, 1995). The first is mediated by $\gamma$ amino-butyric acid (GABA), the most prevalent inhibitory neurotransmitter in the mammalian brain. Nevertheless, prolonged wakefulness and pharmacologically stimulated GABA-ergic inhibition induced different effects in the sleep EEG and these manipulations are likely to promote, therefore, separate neurophysiological processes (Landolt et al, 2000). The second mechanism, which may underlie increased inhibition of thalamo-cortico-thalamic and cortical cells following sleep deprivation, is mediated by amplified neuronal potassium conductance $\left(\mathrm{gK}^{+}\right)$. While nonREM sleep might be regulated by multiple biochemical mechanisms (Obal and Krueger, 2003), the neuromodulator adenosine is released in response to increased metabolic demand by neurons and glia cells and promotes $\mathrm{gK}^{+}$via activation of G-protein-coupled $\mathrm{A}_{1}$ adenosine receptors. This mechanism has been hypothesized to mediate the homeostatic increase of slow-wave activity after sleep deprivation (Benington and Heller, 1995; Porkka-Heiskanen et al, 2002).

Sleep deprivation-induced changes in subjective sleepiness, the waking EEG, sleep architecture, and the sleep EEG were present after both placebo and caffeine treatment. These changes consisted of the global increase of sleepiness and theta power in waking, enhancement of slow-wave sleep, and the augmentation of low-frequency activity and the reduction of SFA in nonREM sleep. Nevertheless, we found distinct effects of caffeine on EEG markers of sleep homeostasis in waking and subsequent sleep, which supports the hypothesis that caffeine attenuated the buildup of sleep propensity associated with wakefulness. Although one needs to be cautious when comparing physiological mechanisms of sleep regulation and pharmacological interventions, the striking similarity of the effects of caffeine with those of a physiologic reduction of sleep pressure by intermittent naps (Cajochen et al, 2001; Knoblauch et al, 2002) is consistent with the hypothesis of an important role of adenosine and adenosine receptors in the homeostatic regulation of sleep.

\section{ACKNOWLEDGEMENTS}

We thank M Adam and A Gerber for their help with data collection and sleep state scoring, Dr R Dürr for technical support, and Prof. AA Borbély for comments on the manuscript. We declare that we have no competing interests, financial or otherwise. The research was supported by the Swiss National Science Foundation Grants \# 3100-067060.01 (to HPL) and \# 3100A0-10567 (to PA).

\section{REFERENCES}

Aeschbach D, Matthews JR, Postolache TT, Jackson MA, Giesen HA, Wehr TA (1997). Dynamics of the human EEG during prolonged wakefulness: evidence for frequency-specific circadian and homeostatic influences. Neurosci Lett 239: 121-124.

Aeschbach D, Matthews JR, Postolache TT, Jackson MA, Giesen HA, Wehr TA (1999). Two circadian rhythms in the human 
electroencephalogram during wakefulness. Am J Physiol 277: R1771-R1779.

Akerstedt T, Gillberg M (1990). Subjective and objective sleepiness in the active individual. Int J Neurosci 52: 29-37.

Benington JH, Heller HC (1995). Restoration of brain energy metabolism as the function of sleep. Prog Neurobiol 45: 347-360.

Borbély AA, Achermann P (2000). Sleep homeostasis and models of sleep regulation In: Kryger $\mathrm{MH}$, Roth T, Dement WC (eds). Principles and Practice of Sleep Medicine. WB Saunders Company: Philadelphia, PA. pp 377-390.

Borbély AA, Baumann F, Brandeis D, Strauch I, Lehmann D (1981). Sleep deprivation: effect on sleep stages and EEG power density in man. Electroencephalogr Clin Neurophysiol 51: 483-493.

Cajochen C, Brunner DP, Kräuchi K, Graw P, Wirz-Justice A (1995). Power density in theta/alpha frequencies of the waking EEG progressively increases during sustained wakefulness. Sleep 18: $890-894$.

Cajochen C, Knoblauch V, Kräuchi K, Renz C, Wirz-Justice A (2001). Dynamics of frontal EEG activity, sleepiness and body temperature under high and low sleep pressure. NeuroReport 12: 2277-2281.

Cajochen C, Wyatt JK, Czeisler CA, Dijk DJ (2002). Separation of circadian and wake duration-dependent modulation of EEG activation during wakefulness. Neuroscience 114: 1047-1060.

Dijk DJ, Hayes B, Czeisler CA (1993). Dynamics of electroencephalographic sleep spindles and slow wave activity in men: effect of sleep deprivation. Brain Res 626: 190-199.

Dimpfel W, Schober F, Spüler M (1993). The influence of caffeine on human EEG under resting conditions and during mental loads. Clin Invest 71: 197-207.

Dumont M, Macchi MM, Carrier J, Lafrance C, Hebert M (1999). Time course of narrow frequency bands in the waking EEG during sleep deprivation. NeuroReport 10: 403-407.

Dunwiddie TV, Masino SA (2001). The role and regulation of adenosine in the central nervous system. Annu Rev Neurosci 24: $31-55$.

Finelli LA, Baumann H, Borbély AA, Achermann P (2000). Dual electroencephalogram markers of human sleep homeostasis: correlation between theta activity in waking and slow-wave activity in sleep. Neuroscience 101: 523-529.

Finelli LA, Borbély AA, Achermann P (2001). Functional topography of the human nonREM sleep electroencephalogram. Eur J Neurosci 13: 2282-2290.

Fredholm BB, Bättig K, Holmen J, Nehlig A, Zvartau EE (1999). Actions of caffeine in the brain with special reference to factors that contribute to its widespread use. Pharmacol Rev 51: 83-133.

Haeckel R (1990). Relationship between intraindividual variation of the saliva/plasma- and of the arteriovenous concentration ratio as demonstrated by the administration of caffeine. J Clin Chem Clin Biochem 28: 279-284.

Kaasinen V, Aalto S, Nagren K, Rinne JO (2004). Dopaminergic effects of caffeine in the human striatum and thalamus. NeuroReport 15: 281-285.

Knoblauch V, Kräuchi K, Renz C, Wirz-Justice A, Cajochen C (2002). Homeostatic control of slow-wave and spindle frequency activity during human sleep: effect of differential sleep pressure and brain topography. Cerebr Cortex 12: 1092-1100.
Künkel H (1976). EEG-Spektralanalyse der Coffein-Wirkung. Arzneim-Forsch/Drug Res 26: 462-465.

Landolt HP, Dijk DJ, Gaus SE, Borbély AA (1995a). Caffeine reduces low-frequency delta activity in the human sleep EEG. Neuropsychopharmacology 12: 229-238.

Landolt HP, Finelli LA, Roth C, Buck A, Achermann P, Borbély AA (2000). Zolpidem and sleep deprivation: different effect on EEG power spectra. J Sleep Res 9: 175-183.

Landolt HP, Werth E, Borbély AA, Dijk DJ (1995b). Caffeine intake $(200 \mathrm{mg})$ in the morning affects human sleep and EEG power spectra at night. Brain Res 675: 67-74.

McCormick DA, Bal T (1997). Sleep and arousal: thalamocortical mechanisms. Annu Rev Neurosci 20: 185-215.

Obal Jr F, Krueger JM (2003). Biochemical regulation of non-rapideye-movement sleep. Front Biosci 8: 520-550.

Oellerich M (1980). Enzyme immunoassays in clinical chemistry: present status and trends. J Clin Chem Clin Biochem 18: 197-208.

Porkka-Heiskanen T, Alanko L, Kalinchuk A, Stenberg D (2002). Adenosine and sleep. Sleep Med Rev 6: 321-332.

Porkka-Heiskanen T, Strecker RE, Thakkar M, Bjorkum AA, Greene RW, McCarley RW (1997). Adenosine: a mediator of the sleep-inducing effects of prolonged wakefulness. Science 276: 1265-1268.

Radulovacki M (1993). Adenosine sleep theory. Sleep Res 22: 485.

Rechtschaffen A, Kales A (1968). A Manual of Standardized Terminology, Techniques and Scoring System for Sleep Stages of Human Subjects. National Institutes of Health: Bethesda, MD.

Rosenthal L, Roehrs T, Zwyghuizen-Doorenbos A, Plath D, Roth T (1991). Alerting effects of caffeine after normal and restricted sleep. Neuropsychopharmacology 4: 103-108.

Schwierin B, Borbély AA, Tobler I (1996). Effects of $\mathrm{N}^{6}$ cyclopentyladenosine and caffeine on sleep regulation in the rat. Eur J Pharmacol 300: 163-171.

Stenberg D, Litonius E, Halldner L, Johansson B, Fredholm BB, Porkka-Heiskanen T (2003). Sleep and its homeostatic regulation in mice lacking the adenosine A1 receptor. J Sleep Res 12: 283-290.

Steriade M (2003). The corticothalamic system in sleep. Front Biosci 8: 878-899.

Steriade M, McCormick DA, Sejnowski TJ (1993). Thalamocortical oscillations in the sleeping and aroused brain. Science 262: 679-685.

Sturm A, Clarenbach P (1997). Schlafstörungen. Thieme Verlag: Stuttgart, New York.

Torsvall L, Akerstedt T (1987). Sleepiness on the job: continuously measured EEG changes in train drivers. Electroencephalogr Clin Neurophysiol 66: 502-511.

Van Dongen HP, Price NJ, Mullington JM, Szuba MP, Kapoor SC, Dinges DF (2001). Caffeine eliminates psychomotor vigilance deficits from sleep inertia. Sleep 24: 813-819.

Wurts SW, Edgar DM (2000). Caffeine during sleep deprivation: sleep tendency and dynamics of recovery sleep in rats. Pharmacol Biochem Behav 65: 155-162.

Zylber-Katz E, Granit L, Levy M (1984). Relationship between caffeine concentrations in plasma and saliva. Clin Pharmacol Ther 36: 133-137. 